\title{
A PRODUÇÃO DE SENTIDOS DOS ESTUDANTES POR MEIO DO REENDEREÇAMENTO DE UM AUDIOVISUAL POR UMA PROFESSORA DE QUÍMICA
}

\author{
MEANING PRODUCTION BY STUDENTS IN A CHEMISTRY TEACHER'S VIDEO \\ READDRESSING
}

\begin{abstract}
Gisele Abreu Lira Corrêa dos Santos ${ }^{1}$, Luiz Augusto Coimbra de Rezende Filho ${ }^{2}$
\end{abstract}
Recebido: maio/2019 Aprovado: junho/2021

\begin{abstract}
Resumo: Este trabalho teve como objetivo investigar, por meio da noção de reendereçamento, como o uso que uma professora de Química fez de uma obra audiovisual atuou na construção dos sentidos produzidos pelos estudantes de ensino médio profissionalizante para jovens e adultos. A pesquisa utilizou-se do método da observação da aula com o uso do vídeo associado a gravações de voz e entrevistas. O reendereçamento diz respeito às adaptações e mediações feitas por professores em obras audiovisuais para que estes cumpram uma função educativa. Os resultados apontam o papel ativo dos alunos espectadores na negociação de sentido a partir dos materiais levados pela professora e dos posicionamentos dela em relação à discussão de um problema ambiental. Concluímos que, no que diz respeito ao reendereçamento, os alunos aceitaram a proposta de assistir ao vídeo de acordo com a estratégia da professora, ou seja, para buscar informações sobre um problema ambiental. Mas, em relação ao direcionamento da leitura do vídeo na construção dos sentidos dos estudantes, houve uma prevalência do significado preferencial do vídeo sobre o reendereçamento feito pela professora.
\end{abstract}

Palavras-chave: audiovisual, reendereçamento, ensino de Química.

\begin{abstract}
This paper aimed to investigate how a Chemistry teacher uses videos to construct meaning during an educational activity in a high school adult teaching modality class. Supported by the notion of readdressing, the research used the method of observation, video and voice recordings and interviews. Readdressing refers to the adaptations and mediations made by teachers in a given audiovisual material to fulfill an educational objective. The results show that the students had an active role during the teaching activity by the way they negotiated the meanings and the readings of the video with the teacher's discourse and positions regarding environmental issues. We may conclude the students accepted the teacher's readdressing strategy to watch the video to gather information about an environmental issue. However, they did not accept completely the reading direction given by her, since there has been a prevalence of the preferential meaning of the video in the students' understandings over the readdressing made by the teacher.
\end{abstract}

Keywords: audiovisual, readdressing, Chemistry teaching.

\section{Introdução}

O processo de ensino-aprendizagem da Química tem sido objeto de grande número de pesquisas, em vista de se promover abordagens didáticas que superem a forma descontextualizada, fragmentada e distante do cotidiano em que a Química tem sido ensinada.

ORCID iD: 0000-0002-3365-2780 - Doutora em Educação em Ciências e Saúde - UFRJ. Professora da Educação Básica e do Mestrado Profissional em Práticas de Educação Básica do Colégio Pedro II, Rio de Janeiro, RJ, Brasil. Correspondência: Campo de São Cristóvão, 177, São Cristóvão, CEP:20921-903, Rio de Janeiro, RJ, Brasil. giselealcsantos@cp2.g12.br.

2 ID ORCID iD: 0000-0002-6466-3335 - Doutor em Comunicação e Cultura - UFRJ. Professor Associado Instituto Nutes/UFRJ, Rio de Janeiro, RJ, Brasil. Correspondência: Av. Carlos Chagas Filho, 373, Centro de Ciências e Saúde, Bloco A, sala 12, Cidade Universitária, Ilha do Fundão, CEP: 21941-902, Rio de Janeiro, RJ, Brasil. luizrezende@ufrj.br 
Em revisões bibliográficas de publicações em eventos e periódicos, Locatelli, Zoch e Amaral (2015) e Bouzon et al. (2018) verificaram um aumento no número de pesquisas sobre ensino de Química com abordagens na tríade Ciência, Tecnologia e Sociedade (CTS).

A partir desse movimento atual de busca pela superação de um ensino de Química reduzido e linear, não podemos ignorar que o universo audiovisual que nos cerca pode vir ao encontro como uma resposta a esta problemática. Lufti (1997) nos propõe um estudo da Química temático no qual os temas estejam articulados às vivências dos estudantes, em vez de uma sequência formal de conteúdos. Nesta abordagem temática, o uso do vídeo, segundo a literatura, é um grande aliado para abordar os conteúdos da Química articulados a outras áreas de conhecimentos e agregados a aspectos socioculturais e ambientais. No entanto, a forma como essa contribuição se dá no ensino de Química permanece pouco pesquisada e evidenciada, conforme revisões bibliográficas de Rezende Filho, Pereira e Vairo (2012) e Berk e Rocha (2019).

Verifica-se que o uso do vídeo em sala de aula em experiências relatadas em publicações científicas ainda é frequentemente concebido como uma ferramenta para diversificar e motivar o ensino. Além disso, observa-se a sua utilização muito relacionada ao conteúdo, de forma que seu uso só se justificaria para auxiliar a compreensão e assimilação de determinado conceito científico (BERK; ROCHA, 2019). Esta concepção de vídeo, apenas como um recurso para o estímulo, a ilustração ou o reforço da aprendizagem, é o que Nelson Pretto considera como tributário de uma perspectiva da instrumentalidade. Em suas palavras, o vídeo seria apenas "um animador da velha educação" (PRETTO, 2013, p.138).

Predominantemente alinhados na perspectiva da instrumentalidade temos a utilização do vídeo nos trabalhos de Almeida, Castro e Cavalcanti (2014), como meio de permitir a visualização de representações do átomo; de Gomes, Carbo e Queiroz (2015), como meio de permitir a visualização de processos químicos; de Benite et al. (2015); e de Leão, Rehfeldt e Marchi (2015), como alternativa para permitir a visualização de experimentações.

Pretto (2013) defende que a utilização do vídeo possa ser feita além da instrumentalização, sob a perspectiva do fundamento. Esta considera o audiovisual como um centro irradiador de conhecimento e o professor como um articulador criativo do processo educativo. Esta forma sugerida de uso pretende atender as necessidades de não somente preparar os alunos para exames e vestibulares, mas principalmente para uma formação autônoma e crítica do estudante para a vivência no mundo contemporâneo.

Na perspectiva de uso do vídeo como fundamento, encontramos a utilização do vídeo no trabalho de Silva, Xavier e Dantas Filho (2015) para possibilitar o enfoque CTSA (Ciência, Tecnologia, Sociedade e Ambiente); de Costa et al. (2016), para a contextualização do conteúdo; de Silva, Ferreira e Silveira (2016), para a problematização de conteúdos; e de Gaúna, Pereira e Recena (2017), para sensibilizar e instigar os alunos para o debate de questões socioambientais, todas essas propostas apresentam o professor com um papel mediador central.

Assim, entendemos que o professor tem um papel importante junto à mediação de sentidos de uma obra audiovisual em um contexto de ensino, pois a sua atuação pode promover reflexões de forma a conduzir ou não os sentidos produzidos pelos estudantes. O professor pode 
mediar tanto no sentido de limitar os sentidos construídos, centrados nos conteúdos curriculares apenas, como pode proporcionar uma leitura mais ampla, que contribui para a formação de um aluno espectador crítico sobre a presença da Química na sociedade, por exemplo.

Partindo do pressuposto segundo o qual as ações dos professores como mediadores tanto podem tentar controlar quanto ampliar as leituras dos estudantes frente à exibição de audiovisuais, configurou-se o problema desta pesquisa. Este foi traduzido na forma da seguinte pergunta: de que forma os modos como os professores de Química usam obras audiovisuais (vídeos ou filmes) se relacionam com a construção dos sentidos sobre elas pelos estudantes?

Nesse sentido, essa pesquisa se justifica pela importância de compreender as relações entre as ações do professor na exibição de vídeos em aula e a produção de sentidos pelos estudantes. Além disso, entender de que maneira a (re)construção do lugar do aluno como espectador interfere sobre o processo de ensino-aprendizagem. 0 entendimento destas relações poderá contribuir para uma incorporação consistente desse recurso no contexto educativo.

O objetivo foi investigar, por meio da noção de reendereçamento, como o uso que uma professora de Química fez de uma obra audiovisual atuou na construção dos sentidos produzidos pelos estudantes do ensino médio profissionalizante para jovens e adultos. Para isso, foram identificados o endereçamento e o significado preferencial da obra audiovisual utilizada pela professora; descritas as suas ações e atividades; e estabelecidas as relações entre as ações da professora com a obra e as leituras produzidas pelos estudantes quanto à construção/reconstrução de sentidos sobre o vídeo exibido.

\section{Referencial Teórico}

O referencial que sustenta a nossa pesquisa em relação ao uso do audiovisual pelo professor e a produção de sentidos pelos estudantes vem da teoria do cinema, adaptada para o campo da educação. Os teóricos do cinema desenvolveram a noção de modo de endereçamento a partir de referenciais da Teoria Literária e dos Estudos Culturais para compreender questões, como a relação do texto fílmico e a experiência do espectador.

A autora Ellsworth (2001) afirma que os produtores fazem suposições sobre o seu público ao criar um filme, que poderiam ser resumidas em uma pergunta: "Quem este filme pensa que você é?". Estas suposições por parte da produção geram "traços intencionais e nãointencionais" no filme, que seriam o que ela define como modo de endereçamento.

O modo de endereçamento está relacionado com a necessidade de comunicar para alguém, sendo uma estrutura invisível que convoca o público a um posicionamento em relação ao texto. Como a autora considera que não existe um único modo de endereçamento em um filme, pode-se supor que exista um endereçamento principal construído para que agrade e faça sentido ao público que foi idealizado.

Para que o filme seja compreendido no sentido que foi pretendido pelo produtor, o espectador deve assumir certas posições que the são oferecidas a ocupar pelo modo de 
endereçamento. Caso o espectador não ocupe essas posições, é provável que faça uma leitura do filme distinta do previsto, ou até mesmo em direção contrária aos modos de endereçamento.

Hall (2003) considera que toda obra tem em sua mensagem um sentido principal que foi pretendido pelos produtores, que seria o seu significado preferencial. Em sua perspectiva, os espectadores são ativos no processo de recepção. Assim poderiam se posicionar em aceitação, de forma negociada ou mesmo resistindo ao significado preferencial. $\mathrm{O}$ autor afirma que, na maioria das vezes, nós lemos em uma posição negociada devido à atuação de nossas subjetividades e experiências socioculturais na construção dos sentidos.

Assim, a mesma autora (ELLSWORTH, 2001) nos coloca que como os produtores de cinema estão distantes de seus espectadores reais, o público pode não ser exatamente da forma como ele foi imaginado, o que pode originar "erros" de endereçamento. Essas imprecisões das suposições dos produtores podem resultar na inclusão e/ou exclusão de determinados públicos ou camadas do público.

No campo pedagógico, Ellsworth (2001) considera que os professores podem utilizar da compreensão do conceito de modo de endereçamento para mudar, controlar ou influenciar a resposta de seus estudantes, ou mesmo para ensiná-los como subverter ou resistir a um determinado conteúdo, filme ou currículo. A autora sugere que seria produtivo que os professores possam se utilizar da diferença de respostas dos seus alunos para o aprendizado.

O reendereçamento do audiovisual (REZENDE FILHO et. al. 2015) é inspirado no conceito de endereçamento, já que é um processo que envolve as variações no modo ao qual o audiovisual será adaptado para um público e/ou um contexto para os quais não foi produzido, podendo surgir modificações do seu endereçamento original. Como atuamos no campo educacional, pesquisamos o reendereçamento a partir de adaptações feitas pelos professores para a utilização de audiovisuais em situações didáticas.

A noção de reendereçamento do audiovisual assemelha-se ao conceito utilizado na área da literatura, sendo neste campo o fenômeno do reendereçamento a produção de uma publicação destinada para crianças e jovens a partir de obras literárias produzidas originalmente para adultos (DIAS; SOUZA, 2016). Na obra seriam feitas edições para que ela fosse claramente identificada com as necessidades de leitura de um novo público.

A respeito da produção de sentidos, já citamos anteriormente a atuação de nossas subjetividades e experiências socioculturais em leituras negociadas. Uma importante contribuição que Roger Odin (2005) nos traz diz respeito também ao papel atribuído aos espaços onde um filme é exibido na produção de sentidos pelo espectador. Segundo o autor, por exemplo, o espaço escolar acaba por nos "impor" um modo de assistir para extrair informações do audiovisual, e não uma leitura com finalidade de diversão. Logo, uma obra pode ter o seu sentido modificado e constituído de acordo com o seu contexto de exibição pelo espaço físico e até mesmo pela situação de se estar assistindo-a sozinho ou acompanhado.

A situação de assistir um audiovisual acompanhado é chamada coviewing. De acordo com uma revisão feita por Sá (2015), os estudos de coviewing começaram na década de 1970, com investigações voltadas a pais e filhos que assistiam juntos "Vila Sésamo". Essas pesquisas apontaram que a presença dos pais fazia com que as crianças tivessem um melhor 
aproveitamento dos conteúdos educativos do programa e um melhor aprendizado. Os estudos de coviewing evoluíram atualmente, e sua aplicação não se limita mais à televisão, já que as mídias digitais deram lugar a outras práticas de visualização de audiovisuais. Temos, nos dias de hoje, práticas de coviewing relacionadas à assistência com múltiplas telas e espectadores distanciados espacialmente compartilhando suas experiências de visualização.

No reendereçamento, as ações de adaptação do mediador podem convergir com ou contrariar as informações ou características da obra audiovisual original. Edições feitas podem modificar completamente a forma em que a história é narrada, ou que os personagens são representados, entre outros aspectos, por exemplo. Sendo assim, a mediação do professor, na forma de uma ação similar ao coviewing, é uma ação que pode interferir sobre a produção de significados. O reendereçamento pode também implicar em um deslocamento da posição do espectador para ver a obra audiovisual.

Na próxima secção serão apresentadas as etapas desta pesquisa, desde a natureza e o desenho da pesquisa aos procedimentos de coleta, de análise e de discussão de dados.

\section{Metodologia}

Esta foi uma pesquisa de natureza empírica com abordagem qualitativa, pois se pretendeu aprofundar os conhecimentos sobre as ações e relações humanas. A estratégia de investigação pertinente a este estudo foi a observação, que é definida como um processo pelo qual o pesquisador se coloca como observador da investigação científica em uma relação direta no espaço social da pesquisa (MINAYO, 2008).

O local escolhido para ser realizada a pesquisa foi o Colégio Pedro II. A escolha desta instituição de ensino se deu pela proximidade da pesquisadora com o estabelecimento de ensino; por ser um centro de referência de ensino, e pelo fato de que a instituição oferece condições físicas e estruturais necessárias à execução da pesquisa. A aplicação deste projeto concentrou-se no nível de ensino médio.

Em relação aos procedimentos metodológicos, a pesquisa foi desenvolvida a partir das seguintes etapas: seleção do local; levantamento exploratório dos participantes por meio de questionários; seleção da professora participante da pesquisa; análise fílmica dos audiovisuais exibidos em uma aula; observação da aula com registro de áudio e anotações; análise da produção de sentidos dos estudantes e entrevista com a docente.

A investigação inicialmente previu uma consulta exploratória aos professores de Química por meio do envio por e-mail de um questionário semiaberto preliminar, que procurou verificar a utilização, a frequência e os gêneros de audiovisuais usados pelos professores em aula. Aos respondentes do questionário preliminar foi enviado um questionário complementar para o aprofundamento de algumas questões, como por exemplo de que modo (motivações e ações) é feita a exibição de vídeos.

No ano de 2018, apenas uma docente, que atendeu aos critérios de frequência e modo de uso do audiovisual, aceitou participar da pesquisa, que consistiu basicamente em uma atividade de observação de sua aula com a exibição de vídeos. A partir do seu consentimento foi solicitado ter acesso ao seu planejamento para a aula em que exibiria os vídeos. Não 
fornecemos esclarecimentos sobre a fundamentação teórica do trabalho para que as ações da professora não fossem influenciadas com o objetivo de atender aos interesses da pesquisa.

A professora e os quinze estudantes de sua turma que aceitaram participar foram esclarecidos da sua voluntariedade e não obrigatoriedade de participação na pesquisa, mediante a entrega do Termo de Consentimento Livre e Esclarecido (TCLE). Para garantir o anonimato, os estudantes participantes da pesquisa serão identificados pela letra $A$ seguido de um numeral, por exemplo: A1, A2, A3 e assim por diante, havendo o uso de Ax quando por algum motivo o aluno não for identificado.

A partir do conhecimento de quais vídeos seriam exibidos em aula, estes foram assistidos e analisados previamente à observação da aula. Utilizou-se a análise fílmica segundo o referencial de Vanoye e Goliot-Lété (1994), objetivando a identificação do endereçamento e do significado preferencial da obra. A análise do endereçamento anterior à observação em aula é imprescindível para identificar se a professora manteve o endereçamento original do vídeo selecionado ou se o adaptou (reendereçamento) de alguma forma durante a exibição para atingir os objetivos do seu plano de aula.

Tomando-se como base os procedimentos e resultados de pesquisa anterior sobre reendereçamento de vídeo em contexto escolar (DISSAT; REZENDE FILHO, 2019), foram definidos alguns focos de observação nas ações da professora em sala de aula que pudessem constituir o reendereçamento, tais como: a escolha do momento de exibição do vídeo e da apresentação do conteúdo; a edição, pausa, adiantamento ou retrocesso do vídeo; as explicações dos conceitos químicos relacionadas à exibição do vídeo e as conduções dos sentidos associados ao conteúdo do vídeo.

A coleta de dados foi feita por meio de instrumentos de diferentes naturezas: anotações por escrito e gravações de voz da professora sobre a aula; anotações das observações em diário de campo e as gravações de áudio da aula. Segundo Maren (2004), a intersecção de dados de diferentes naturezas obtidos tem por objetivo verificar a coerência e/ou diferença das informações, a fim de tornar possível a validação dos dados.

A observação da aula também objetivou perceber os sentidos produzidos pelos estudantes em relação às leituras do audiovisual mediado pela professora. Se necessário complementar a observação em sala de aula, estavam previstas entrevistas semiestruturadas a estes estudantes. Estas entrevistas não foram necessárias, já que as gravações da aula foram suficientes para perceber os sentidos produzidos por eles.

Posteriormente à atividade de observação em sala de aula foi realizada uma entrevista semiestruturada com a professora com o propósito de buscar mais informações a respeito das motivações, posicionamentos de leitura e o porquê de suas escolhas e adaptações, ou seja, motivações que a levaram a utilizar especificamente aquela obra audiovisual em sala de aula e daquela maneira.

Para a apreciação dos dados de transcrição da aula e das entrevistas, recorremos a um método de análise próprio baseada em alguns fundamentos da técnica de Análise de Conteúdo. Esta técnica de análise da comunicação consiste em procedimentos de descrição dos conteúdos 
das mensagens que visam a constatação de "indicadores (quantitativos ou não) que permitam a inferência de conhecimentos relativos às condições de produção/ recepção (variáveis inferidas) dessas mensagens" (BARDIN, p. 48, 2016).

A partir da atividade realizada buscou-se olhar as possíveis relações que poderiam ser estabelecidas do reendereçamento do audiovisual com as leituras produzidas a partir dos vídeos. Algumas questões, tais quais, o posicionamento do vídeo e da mediação da professora; que ações de reendereçamento foram mobilizadas e que fatores nortearam a produção de sentidos dos estudantes serão discutidas na próxima secção.

\section{Resultados e Discussão}

A partir de uma amostra de quinze professores que utilizam audiovisuais em sala de aula e responderam os questionários, foram feitos os convites para a participação na pesquisa. Recebemos a resposta de uma professora que confirmou uma participação imediata. Ela afirmou ter uma aula planejada com vídeo para a sua turma de 1o ano do ensino médio profissionalizante de jovens e adultos (PROEJA). No dia da aplicação estavam presentes nove alunos de um total de quinze que frequentam, informação fornecida pela professora.

A professora afirmou utilizar regularmente, em suas turmas do PROEJA, vídeos do gênero documentário disponíveis no Youtube com a duração de vinte a trinta minutos, principalmente quando o conteúdo tem relação com a temática de meio ambiente. Também nos informou que posteriormente à exibição do vídeo costumava fazer uma reflexão e/ou um debate sobre o assunto do vídeo.

A pesquisadora solicitou que fossem enviados antecipadamente o tema, os objetivos da aula e os vídeos que seriam exibidos. A docente nos informou que o conteúdo da aula de Química seria "Água e Energia", que seria abordado por meio de duas partes de uma reportagem sobre a construção da hidrelétrica de Belo Monte. Os links dos vídeos foram disponibilizados, e verificou-se que os vídeos eram: "Belo Monte, uma usina polêmica - Parte 1 - A obra" e "Belo Monte, uma usina polêmica - Parte 2 - Os impactos", do programa Jornal da Cultura, da TV Cultura, disponíveis no Canal do Youtube "Jornalismo TV Cultura". O objetivo da aula, segundo o relato da professora, foi promover uma discussão sobre o conteúdo incluindo os aspectos positivos e negativos da construção de uma hidrelétrica, por meio de um debate.

Os vídeos têm o formato de uma reportagem com a fala de especialistas que apresentam os prós e os contras da construção da usina hidrelétrica Belo Monte, no Pará, com ênfase na questão dos impactos negativos. Ainda que estas partes da reportagem tenham procurado apresentar predominantemente uma posição de neutralidade sobre o assunto, percebemos que as imagens e a narração demonstram um posicionamento dos produtores. Abaixo enumeramos algumas das evidências disso, encontradas por meio da análise fílmica.

Esteticamente há uma ênfase na beleza da paisagem ao redor do rio, contrastando com as imagens da construção da obra que representam a destruição desta beleza natural. No que diz respeito à narrativa, os benefícios da construção da usina são mostrados quantitativamente em menor número, com menor duração da fala e rasos em suas justificativas. Já em relação aos 
malefícios, foi proporcionado maior tempo total e apresentadas posições mais elaboradas por seus defensores. Esse posicionamento do discurso foi reforçado pelas argumentações em tom de crítica à construção feitas pelo repórter e pelo comentarista da matéria. Assim, em relação aos aspectos narrativos e estéticos, há um enfoque predominante nos impactos negativos, mostrando um posicionamento em relação à defesa das questões socioambientais.

Há, assim, na reportagem uma alternância dos argumentos prós e contras, com um menor tempo dedicado aos argumentos favoráveis à construção da usina. Na ordem da edição, a última fala é do comentarista convidado a viajar com a reportagem, que estabelece uma conclusão sobre a polêmica. Isso nos permite concluir que a reportagem expressa um posicionamento contrário à construção da usina, sobre o qual quer persuadir o espectador.

O conteúdo foi associado a uma problemática brasileira e a linguagem acessível da reportagem supõe um público amplo, com interesse em informação. Logo, podemos concluir que foi destinado ao telespectador jovem e adulto brasileiro de escolaridades variadas.

A reportagem é constituída de seis partes, mas considerando apenas as duas partes dos vídeos apresentadas aos estudantes, podemos concluir que o vídeo pretendeu apresentar os prós e contras da construção de uma usina hidrelétrica com ênfase na questão dos impactos negativos. A mensagem geral destas partes do vídeo, ou seja, o seu significado preferencial é: "Entre os prós e contras para a construção da usina de Belo Monte, os impactos ambientais e sociais parecem não justificar a sua existência".

Em conversa anterior à aula, a professora explicou que ela utilizaria um texto intitulado "Energia Hidrelétrica", impresso em cópias para os alunos, com o objetivo de complementar as informações dadas pelo vídeo e avaliar a atividade a ser realizada. Esse texto complementar aborda introdutoriamente a importância das fontes energéticas limpas. Ele apresenta a questão da produção e do aproveitamento hidráulico, havendo um destaque para a associação do desenvolvimento econômico do país à produção de energia por meio das hidrelétricas. Em nenhum momento o texto relata os impactos negativos provocados pela construção e implantação de uma usina hidrelétrica em uma localidade. A última página do texto é destacável, para que os alunos preenchessem com as vantagens e desvantagens da energia hidrelétrica a partir da leitura do texto e do vídeo exibido em sala de aula.

Esta estratégia de complementação do conteúdo do vídeo mostrou um tipo de ação de reendereçamento, já que a professora usou essa estratégia para conduzir a compreensão dos alunos em direção aos objetivos da sua aula. Essa ação da leitura anterior do texto impresso, com informações que não faziam parte da reportagem no vídeo, cria um contexto específico que pode modificar o olhar dos alunos para a leitura do vídeo.

No início da aula, a professora antecipou aos estudantes informações sobre o vídeo, tais como o fato de se tratar de uma reportagem sobre a Usina Hidrelétrica de Belo Monte, cuja construção causou muita controvérsia. Ela explicou que a construção de uma usina hidrelétrica precisa criar barragens e desviar o rio, o que acarreta impactos e prejudica a população. Mas, ponderou que é necessária uma preocupação anterior à construção da usina. Assim, a professora se mostrou em concordância que o país deve progredir, mas com uma preocupação em minimizar os impactos ambientais e sociais que o progresso possa causar. 
A professora deixou claro e reforçou a todo momento que ela desejava que os alunos extraíssem do texto e do vídeo informações relacionadas às vantagens e desvantagens da construção de uma usina hidrelétrica. Ela comunicou que no texto os alunos teriam informações em relação ao funcionamento e à importância de uma usina hidrelétrica. Ela complementou que por meio da reportagem os alunos teriam informações em relação à questão dos impactos negativos.

Estes comentários antes da exibição, informando o que os estudantes veriam e quais informações os alunos deveriam reter, também nos mostra uma ação de reendereçamento de mediação visando adaptar o conteúdo da reportagem para a situação de ensino, criar um objetivo de leitura e um foco específico para a visualização do material audiovisual. Assim, a preparação anterior à exibição do vídeo feita pela professora teve como fim explicar que ele deveria ser visto para identificar, entender e aprofundar conteúdos previstos para a aula.

Também anteriormente à exibição do vídeo, a professora teve a preocupação de introduzir conceitos, seja por meio do texto impresso ou pela mediação de sua fala, como por exemplo, sobre a diferença entre energia limpa e energia poluidora. Esta também foi uma estratégia de reendereçamento, já que a apresentação de conceitos não foi desenvolvida pelo texto audiovisual. $O$ acesso a essas informações tende a direcionar a atenção dos estudantes para o trecho de funcionamento da usina que consta na reportagem. Todo esse preparo anterior à exibição do vídeo nos indicou a intenção de criar um contexto de leitura em que os estudantes assistissem ao vídeo no modo documentário (ODIN, 2005), ou seja, para obter informações sobre o tema da aula. Esse foi o objetivo de leitura proposto e informado pela professora.

Após essa explicação, a professora comentou que o vídeo seria exibido em duas partes seguidas sem interrupções e sem comentários. A professora apagou poucas luzes, parecendo estar preocupada em não simular um "clima" de cinema. Esta também é uma ação de reendereçamento, já que a professora pretendeu desta maneira evitar uma experiência ou relação informal ou espontânea com a reportagem. Desta forma, evidenciou a natureza educativa da exibição e do material.

Os alunos assistiram o vídeo em coviewing com a professora. Eles permaneceram em silêncio, prestando atenção até o término da exibição. Finalizados os vídeos, a professora não perguntou sobre a existência de dúvidas, indicando que, na sua percepção, não haveria espaço para dúvidas, já que o conteúdo do vídeo estaria em linguagem clara e acessível.

Assim, no momento anterior à exibição do vídeo houve um predomínio do discurso da professora com a participação dos alunos praticamente nula. No entanto, após a exibição a professora e os alunos iniciaram uma espécie de debate com algumas questões vistas no vídeo e lidas no texto, no qual os alunos modificaram a sua postura de silenciosa para bastante participativa. Uma razão para a mudança de postura dos alunos seria que o compartilhamento de conhecimentos por meio do vídeo, em relação ao assunto tratado, teria feito com que os alunos se tornassem mais participativos na discussão.

A professora iniciou a discussão com os alunos retomando o que foi visto no vídeo com a fala "eles (o vídeo) apresentam a necessidade de ter uma usina, né, e eles falam um pouquinho do impacto que pode causar". Tendo por base a análise de conteúdo de Bardin (2016) e 
considerando como unidades temáticas as palavras "usina" e "impacto", vimos no seu discurso que usina está ligada à palavra "necessidade", enquanto impacto ao adjetivo no diminutivo "pouquinho". Ela afirmou que esta informação foi extraída do vídeo, embora a análise fílmica nos mostre que quantitativamente a questão dos malefícios dos impactos se sobrepõe à necessidade da construção da usina no vídeo.

Este seu posicionamento em aula coincide com a sua leitura do vídeo que, apesar de reconhecer os impactos negativos, considera a energia hidroelétrica uma das melhores fontes de energia no Brasil. Esta informação foi obtida em uma pergunta feita em entrevista à professora posteriormente à aula. Em suas palavras, os dois vídeos:

"trazem a necessidade da construção de uma hidrelétrica, e é lógico, que mostra ali os impactos que vão acontecer na região. Mas, que quando tudo é feito, pensado, seguindo, obedecendo as normas necessárias com a fauna e a flora, os impactos são minimizados".

De acordo com as posições de leitura propostas por Hall (2003), a professora fez uma leitura negociada em relação ao significado preferencial, uma vez que ela considerou que a reportagem trouxe uma mensagem com ênfase a favor da construção da usina de Belo Monte. Essa sua posição diverge de nossa análise, que evidenciou no significado preferencial do vídeo a apresentação dos prós e contras da construção da usina hidrelétrica, mas enfatizou os impactos negativos. Consideramos, assim, a sua mediação do vídeo como uma estratégia de coviewing, buscando controlar a produção de sentido dos estudantes, visto que a professora privilegia os benefícios da construção da usina, o que é um aspecto secundário do significado preferencial do vídeo.

Retornando à descrição da aula, a professora enfatizou em seu discurso o trecho do vídeo que mostra que a empresa responsável pela construção da usina, a Norte Energia, tomou medidas de minimização de impactos negativos com a catalogação e conservação de mudas da vegetação específica da área que será devastada. Novamente, observamos que a escolha em discutir este trecho tende a reforçar o seu discurso segundo o qual, apesar do impacto negativo, a construção é vantajosa.

A partir do comentário do aluno $A 3$ sobre a situação de que a população local vive principalmente da pesca, a professora informou que quando o rio é desviado, os peixes são recolhidos e recolocados. Neste momento da explicação, a professora pareceu subestimar o impacto causado, pois nem toda a fauna aquática é recolhida e recomposta, muitas espécies locais podem ser extintas neste processo. Percebeu-se que a mediação da professora vem se direcionando em um sentido de minimizar os danos e valorizar os aspectos positivos da construção da usina. Outra aluna A1 trouxe o fato de que na área desmatada deveria haver árvores frutíferas. A professora respondeu que foram feitas "mudas" para o replantio. A mesma aluna contradisse a fala da professora: "ah, eu acho isso impossível!". A professora concordou com essa ponderação, dizendo que toda a vegetação já estava lá há um século, se fosse replantada em outra área, isso iria demorar.

Podemos dizer que durante toda esta dinâmica da discussão da reportagem, a professora conduziu os sentidos para que os alunos tivessem uma percepção de que a construção da usina é necessária, mas que deve haver uma preocupação com os impactos negativos, que serão 
minimizados. Porém, como vimos nos trechos anteriores relativos ao desmatamento, os alunos coadunaram entre si uma opinião de discordância, de que o impacto não se remedeia. Um exemplo muito claro está manifestado na palavra "impossível", quando a aluna A1 disse ser impossível recompor a vegetação. A professora, neste momento, reconsiderou o seu posicionamento e se colocou em concordância com os estudantes.

Logo após, a professora conduziu a discussão com um novo argumento para amenizar os impactos negativos, dizendo que a população local é reconduzida para outros trabalhos. Ela argumentou: "As pessoas que moram, que vão deixar de ganhar, de repente pela pesca, trabalham na construção da usina. (...) É mais ou menos isso aí, o acordo que eles fazem". O aluno A3 não aceitou o argumento, explicando que isso modifica a rotina da vida das pessoas. A professora refletiu e concordou: "é um estilo de vida que não é o que ela queria, né?".

Enquanto a professora atenuou os impactos negativos, buscando direcionar os estudantes para que percebessem os benefícios da construção da usina, eles mantiveram as suas argumentações mais próximas ao significado preferencial da reportagem, que enfatizava os impactos negativos.

A seguir, a professora comentou sobre energia limpa, poluição, ciclo da água, recurso renovável e não renovável, definições que não estavam presentes no vídeo. Essa complementação de conteúdo foi feita pela professora para que os alunos pudessem produzir sentidos a partir da introdução de conceitos relacionados à disciplina de Química. Esse comentário trouxe mais um reendereçamento, uma vez que esses conceitos não faziam parte do conteúdo do vídeo e potencialmente modificam a produção de sentido dos estudantes.

A professora reforçou que é uma vantagem a cidade ter mais locomoção pela construção de estradas. O aluno A3 concordou, dizendo que haveria "uma evolução no desenvolvimento local", mas a aluna A1 manifestou uma fala em discordância: "eu já acho que eles destroem uma cultura antiga, eu acho isso".

É importante neste caso, não somente analisar as palavras, como também o tom de voz impresso na fala da aluna A1. Considerar somente a linguagem seria parcial em relação à construção de significados, requerendo a complementação dos seus significados topológicos aos tipológicos (LEMKE, 2010). A aluna expressou revolta na tonalidade de sua pronúncia, logo podemos concluir que ela quis mostrar que o impacto negativo causado não é algo que poderá ser mitigado no futuro. Podemos concluir que para essa aluna as destruições provocadas sobrepujam qualquer benefício que a hidrelétrica possa oferecer.

Esta fala mostrou um sentido oposto ao direcionamento de modificação no significado preferencial da narrativa original feito pela professora, que buscava dar ênfase aos benefícios da construção da hidrelétrica. Percebemos neste trecho, que a professora e essa aluna construíram sentidos divergentes para a mensagem da mesma obra audiovisual.

Em continuidade, a aluna A1 tomou uma posição de confronto, perguntando a professora se a população local não teria energia elétrica. A professora optou em reforçar em seu discurso que o objetivo não seria somente atender a região, mas sim fornecer energia para dezessete estados e sessenta milhões de pessoas. A citação desses grandes números em sua fala tentou 
conferir importância e credibilidade às informações dadas, e mais uma vez minimizar a importância do impacto negativo local.

Em seu discurso percebeu-se palavras marcadas por uma ideia de limitação ("cidadezinha", "comerciozinho pequeno") e de falta ("necessidades bem do sertão", "falta água"), e que a hidrelétrica traria o progresso e o desenvolvimento para a região ("aumento do comércio, a infraestrutura, da cidade em si"). A aluna A1 a princípio pareceu concordar, mas em seguida ela falou que se "ganha de um lado e perde do outro". A professora finalizou, dizendo que se "paga o preço" por esse tipo de energia, mas que não seria somente para a região, e sim para favorecer vários estados. Ao final da aula, a professora se manteve no objetivo de conduzir o debate para os aspectos que mostravam os benefícios da construção de uma hidrelétrica. No entanto, os alunos se mantiveram em discordância no debate.

\section{Considerações Finais}

Este trabalho procurou analisar como se dá a construção de sentidos em uma aula com exibição de audiovisuais. $O$ conceito de modo de endereçamento permite compreender que uma obra possui orientações que fazem o espectador entender se ela se destina a ele ou não. Por outro lado, o reendereçamento tem por objetivo controlar, direcionar ou modificar os sentidos produzidos pelos estudantes a partir da exibição da obra.

A professora participante do estudo relacionou os conhecimentos de Química a uma questão social por meio de uma reportagem audiovisual que abordou a construção polêmica de uma usina hidrelétrica. Esta estratégia propiciou que o conhecimento da Química fosse abordado de uma forma não sistematizada e não fragmentada, para que os estudantes pudessem perceber que os conhecimentos socialmente utilizados são os mesmos transmitidos nas escolas.

Nossas análises nos permitiram perceber que os alunos se posicionaram em uma leitura do vídeo bem semelhante à que consideramos ter sido construída pelos produtores. Não podemos afirmar que isso se deveu necessariamente aos discursos visuais e narrativos da obra, já que os fatores individuais sociais e subjetivos, bem como os objetivos e as condições de visualização também poderiam interferir na produção de sentidos.

Percebemos que a professora fez uma leitura divergente do significado preferencial da obra, e assim tentou construir por meio da mediação outro lugar de leitura para os seus alunos, conforme seus objetivos de ensino. A mediação se fez principalmente pela inserção de conteúdos e por direcionamentos no debate. Mas, observamos resistências por parte dos estudantes à leitura e a alguns objetivos da professora. Assim, ficou evidente o papel ativo dos alunos como espectadores, já que eles negociaram a significação a partir dos materiais levados pela professora e dos posicionamentos dela.

As mediações feitas pela professora se caracterizaram como estratégias de reendereçamento no que diz respeito à inserção de conceitos científicos e do coviewing como tentativa de influência/controle sobre a leitura dos alunos. No entanto, fruto dessas interações, ocorreram algumas negociações de sentido por parte da professora, que fez reconsiderações 
em seu posicionamento, colocando-se por vezes em concordância com a leitura de seus estudantes. Percebemos, assim, que essa dinâmica de interação entre a professora e os estudantes construiu diferentes leituras do conteúdo do audiovisual na situação de sala de aula.

Assim, podemos concluir que no que diz respeito ao reendereçamento os alunos aceitaram a proposta de assistir ao vídeo de acordo com a estratégia da professora, ou seja, compartilharam informações sobre um problema ambiental e o discutiram à luz de conceitos científicos químicos. Mas, em relação ao direcionamento da leitura do vídeo na construção dos sentidos pelos estudantes a respeito dos benefícios e impactos negativos da construção de uma hidrelétrica, houve uma prevalência do significado preferencial do vídeo sobre o reendereçamento feito pela professora.

Consideramos que este estudo nos mostrou aspectos fundamentais da abordagem, intenção e ação docente em aula com exibição de audiovisual. Desta forma, este estudo evidencia que esses aspectos são relevantes para o trabalho docente com audiovisual, o que poderá trazer contribuições para processos formativos docentes para o uso do audiovisual no ensino-aprendizagem. Estudos posteriores procurarão investigar que conhecimentos docentes são necessários para reendereçar um audiovisual, bem como as funções e os resultados do uso de estratégias de reendereçamento audiovisual no ensino.

\section{Referências}

ALMEIDA, T. A.; CASTRO, C. F.; CAVALCANTI, E. L. D. A influência da linguagem audiovisual no ensino e na aprendizagem em aulas de Química. Revista Tecnologias na Educação, v. 6, n. 11, p. 1-17, dez. 2014. ISSN 1984-4751.

BARDIN, L. Análise de conteúdo. Tradução de Luís Augusto Pinheiro. 1. ed. São Paulo: Edições 70, 2016.

BELO MONTE, uma usina polêmica - Parte 1 - A obra. Produção de Patrícia Monken. Publicado pelo Canal Jornalismo TV Cultura, 2002. (7min 25s). Disponível em: https://www.youtube.com/watch?v=YGL9k5Zpp1w\&t=78s. Acesso em 22 jan. 2019.

BELO MONTE, uma usina polêmica - Parte 2 - Os impactos. Produção de Patrícia Monken. Publicado pelo Canal Jornalismo TV Cultura, 2002. (6min 44s). Disponível em: https://www.youtube.com/watch?v=qwKp1dENOX0\&t=150s. Acesso em 22 jan. 2019.

BENITE, C. R. M.; BENITE, A. M. C; GONÇALVES, L. P. S.; MARQUES JÚNIOR, J. G. O uso das TIC'S como alternativa para a experimentação no ensino de Química. Enciclopédia Biosfera, Goiânia, v. 11, n. 20 , p. 611-619, 2015. ISSN 2317-2606.

BERK, A.; ROCHA, M. O uso de recursos audiovisuais no ensino de ciências: uma análise em periódicos da área. Revista Contexto \& Educação, v. 34, n. 107, p. 72-87, 2019. ISSN 2179-1309.

BOUZON, J. D.; BRANDÃO, J. B.; SANTOS, T. C.; CHRISPINO, A. O Ensino de Química no Ensino CTS Brasileiro: Uma Revisão Bibliográfica de Publicações em Periódicos. Química Nova na Escola, São Paulo, v. 40, n. 3, p. 214-225, ago. 2018. ISSN 2175-2699. 
COSTA, M. A.; VASCONCELOS, T. M.; OLIVEIRA, Y. A.; FIELD'S, K. A. P.; SANTOS, R. G. Lixo e Sociedade: contextualização por meio de uma abordagem CTSA no ensino de Química. Revista Brasileira de Ensino de Química, v. 11, n. 2, p. 51-62, jul. 2016. ISSN 1809-6158.

DIAS, A. C. P.; SOUZA, R. C. O projeto gráfico como mediador de leitura: o caso do reendereçamento. Pensares em Revista, São Gonçalo-RJ, n.9, p.62-81, 2016. ISSN 2517-2215.

DISSAT, E; REZENDE FILHO, L. A. C. Endereçamento e Reendereçamento no uso de um vídeo por uma professora de ciências. Revista Brasileira de Ensino de Ciência e Tecnologia, Ponta Grossa, v. 12, n.1, p. 198-220, jan./abr. 2019. ISSN 1982-873X.

ELLSWORTH, E. Modo de endereçamento: uma coisa de cinema, uma coisa de educação também. In: SILVA, T. T. Nunca fomos humanos: metamorfoses da subjetividade contemporânea. Belo Horizonte: Autêntica, 2001. p. 7-76.

GAÚNA, M. G.; PEREIRA, A. S.; RECENA, M. C. P. Vídeos e animações no ensino de Química: Problematizando o surgimento e expansão do setor sucroalcooleiro na região de Dourados - MS. Educação e fronteiras on-line, Dourados, v. 7, n. 21, p. 49-58, set./dez. 2017. ISSN 2237-258X.

GOMES, I. M.; CARBO, L.; QUEIROZ, E. M. G. Ensino de Química associado à indústria sucroalcooleira na Escola Estadual Antônio Ferreira Sobrinho, na cidade de Jaciara, Mato Grosso, Brasil. South American Journal of Basic Education, Technical and Technological, v. 2, n. 2, p. 120-133, 2015. ISSN 2446-4821.

HALL, S. Reflexões sobre o modelo de codificação/decodificção: Uma entrevista com Stuart Hall. In: SOVIK, L (org.). Da diáspora: Identidades e mediações culturais. Tradução de Adelaine La Guardia Resende et al. Belo Horizonte: UFMG; Brasília: Unesco, 2003. cap. 4, p. 353-386.

LEÃO, M. F.; REHFELDT, M. J. H.; MARCHI, M. I. Produção de vídeos com atividades experimentais para dinamizar o estudo dos ciclos biogeoquímicos e favorecer a construção de aprendizagens com significado. Revista Tecnologias na Educação, v. 7, n. 12, p. 1-11, 2015. ISSN 1984-4751.

LEMKE, J. L. Letramento multimidiático: Transformando significados e mídias. Trabalhos em Linguística Aplicada, Campinas, v. 49, n. 2, p. 455-479, jul/dez. 2010. ISSN 2175-764X.

LOCATELLI, A.; ZOCH, A. N; AMARAL, L. C. Z. Enfoque CTS no ensino de Química: Uma pesquisa do "Estado da Arte". Ensino de Ciências e Tecnologia em Revista, v.5, n.1, p.34-47, jan/jun. 2015. INSS 2237-4450.

LUFTI, M. Abordagem sociológica do ensino de Química. Ciência \& Ensino, n. 3, p. 7-9, dez. 1997. ISSN 1414-5111.

MAREN, J. M. V. D. Le cadre conceptuel et méthodologique. In: MAREN, J. M. V. Méthodes de recherche pour l' education: Méthodes en Sciences Humaines. 2. ed. Monreal: De Boeck, 2004. cap. 17.502 p.

MINAYO, M. C. S. (org.) et al. Pesquisa Social: teoria, método e criatividade. 27. ed. Petrópolis: Vozes, 2008. $109 \mathrm{p}$. 
MORAN, J. M. O vídeo na sala de aula. Comunicação \& Educação, v. 2, p. 27-35, 1995. ISSN 23169125.

ODIN, R. A questão do público: Uma abordagem semiopragmática. In: RAMOS, F. Teoria Contemporânea do Cinema. São Paulo: Senac, v. II, 2005. p. 27-45.

PRETTO, N. D. L. A educação num mundo de comunicação. In: PRETTO, N. D. L. Uma escola sem/com futuro: educação e multimídia. 8ª ed. Salvador: Edufba, 2013. p. 119-154.

REZENDE FILHO, L. A. C.; PEREIRA, M. V.; VAIRO, A. C. Recursos audiovisuais como temática de pesquisa em periódicos brasileiros de Educação em Ciências. Revista Brasileira de Pesquisa em Educação em Ciências, v. 11, n. 2, p. 183-204, 2012. ISSN 1806-5104.

REZENDE FILHO, L. A. C.; BASTOS, W. G; PASTOR JUNIOR, A. A.; PEREIRA, M. V. e SÁ, M. B. Contribuições dos estudos de recepção audiovisual para a educação em ciências e saúde. Alexandria: Revista de Educação em Ciência e Tecnologia, Florianópolis, v. 8, n. 2, p. 143-161, jun. 2015. ISSN 1982-5153.

SÁ, F. P. The Co-Viewing 2.0: Detaching From History and Applying in the New Media Age. Culture, v. 11, p. 55-64, 2015.

SILVA, G. N.; XAVIER, K. A.; DANTAS FILHO, F. F. Educação em Química: A TIC vídeo como recurso didático no processo de ensino e aprendizagem de polímeros. Revista Tecnologias na Educação, v. 7, n. 13, p. 1-11, dez. 2015. ISSN 1984-4751.

SILVA, N. S.; FERREIRA, A. C.; SILVEIRA, K. P. Ensino de modelos para o átomo por meio de recursos multimídia em uma abordagem investigativa. Química Nova na Escola, São Paulo, v. 38 , n. 2, p. 141-148, mai. 2016. ISSN 2175-2699.

VANOYE, F.; GOLIOT-LÉTÉ, A. Ensaio sobre a análise fílmica. 6. ed. Campinas: Papirus, 1994. 